\title{
A role for amygdaloid PKA and PKC in the acquisition of long-term conditional fear memories in rats
}

\author{
Ki A. Goosens a, William Holt a , Stephen Maren ${ }^{\mathrm{a}, \mathrm{b}, *}$ \\ ${ }^{a}$ Department of Psychology, University of Michigan, 525 E. University Ave., Ann Arbor, MI 48109-1109, USA \\ ${ }^{\mathrm{b}}$ Neuroscience Program, University of Michigan, 525 E. University Ave., Ann Arbor, MI 48109-1109, USA
}

Received 25 February 2000; received in revised form 28 March 2000; accepted 29 March 2000

\begin{abstract}
Although there is great interest in the cellular mechanisms underlying Pavlovian conditioning, few studies have directly examined the contribution of intracellular signaling pathways in the amygdala to the acquisition and expression of conditional fear memories. In the present study, we examined this issue by infusing 1-(5'-isoquinolinesulfonyl)-2-methylpiperazine (H7), a potent inhibitor of both protein kinase C (PKC) and cAMP-dependent protein kinase (PKA), directly into the amygdala prior to fear conditioning or retention testing. We found that infusion of $\mathrm{H} 7$ prior to training attenuated long-term conditional fear in a dose-dependent manner (Experiment 1), but short-term fear memories were spared. The contribution of protein kinases to conditional fear was region-specific within the amygdala: infusion of $\mathrm{H} 7$ into the basolateral amygdala (BLA) but not the central nucleus of the amygdala (CEA) resulted in attenuated freezing (Experiment 2). Moreover, the deficits in fear conditioning produced by PKA/PKC inhibition were not modality-specific, insofar as intra-BLA H7 reduced both contextual and auditory fear. The effects of $\mathrm{H} 7$ on conditional freezing were not attributable to either state-dependency or performance deficits (Experiment 3). Together, these experiments suggest that amygdaloid PKA and PKC play an important role in the acquisition of fear memories. (C) 2000 Elsevier Science B.V. All rights reserved.
\end{abstract}

Keywords: Amygdala; Kinase; Context; Tone; LTP; Learning; Memory; Fear conditioning

\section{Introduction}

Many studies indicate that the basolateral complex of the amygdala is a critical locus of plasticity during associative fear learning [5]. Neurotoxic lesions of the basolateral amygdala (BLA) result in deficits in both the acquisition and expression of conditional fear $[12,18,21]$ and associative conditional activity develops in neurons of the BLA $[26,27]$ during fear conditioning. A putative cellular mechanism for Pavlovian fear conditioning and the associative neuronal changes that accompany this form of learning is long-term potentiation (LTP) [19]. LTP has been demonstrated in the BLA after high-frequency stimulation of afferents that

\footnotetext{
* Corresponding author. Tel.: + 1-734-9366532; fax: + 1-7347637480

E-mail address: maren@umich.edu (S. Maren).
}

carry either contextual [22] or auditory $[4,7,28]$ information to amygdala neurons during fear conditioning. Fear conditioning also induces LTP-like changes in the BLA [24,29] and transgenic mice deficient in amygdaloid LTP exhibit deficits in long-term fear memories [3]. Moreover, infusion of $N$-methyl-D-aspartate (NMDA) receptor antagonists into the BLA blocks both conditional freezing [11,21] and fear-potentiated startle [25], and impairs the induction of amygdaloid LTP [7,22].

Although both amygdaloid NMDA receptor activation and LTP appear to be critical steps in the acquisition of conditional fear, little is known concerning the intracellular biochemical events subsequent to NMDA receptor activation that are involved in the acquisition of conditional fear memories. It has recently been demonstrated that cAMP-dependent protein kinase (protein kinase A or PKA) activation is involved in the 
expression of an early phase of amygdaloid LTP [7]. Activation of the cAMP response element (CRE), thought to reflect PKA activity [9], has been demonstrated in the amygdala after fear conditioning [10]. Furthermore, shock-induced stress has been shown to increase protein kinase $\mathrm{C}$ (PKC) activity in the amygdala [32]. Given the involvement of these protein kinases in amygdaloid LTP and fear conditioning, one might expect that inhibitors of PKA and PKC activity would attenuate fear conditioning. Consistent with this prediction, it has recently been reported that PKA inhibitors impair the acquisition of fear conditioning $[2,31]$. However, these studies did not specifically target protein kinases in the amygdala because the inhibitors were administered intracerebroventricularly. Therefore, it is unclear whether the amygdala is a critical locus of kinase activity during fear conditioning. In the present experiments, we have addressed this question by infusing 1-(5'-isoquinolinesulfonyl)-2-methylpiperazine (H7), a potent PKA/PKC inhibitor, directly into the amygdala prior to Pavlovian fear conditioning in rats. Our results reveal that amygdaloid PKA and PKC have an important role in the establishment of long-term conditional fear memories.

\section{Materials and methods}

\subsection{Subjects}

Adult male Long-Evans rats (200-224 g) were obtained from a commercial supplier (Harlan SpragueDawley, Indianapolis, IN) and individually housed in standard stainless-steel hanging cages on a 14:10 h light-dark cycle (lights on at 07:00 h). Food and water was provided ad libitum. Rats were handled for 30 $\mathrm{s} /$ day for 5 days to acclimate them to the experimenters.

\subsection{Surgery}

One week before behavioral testing, rats were implanted with guide cannulas (26 gauge; Plastics One, Roanoke, VA) aimed at the BLA or CEA. Rats were anaesthetized with sodium pentobarbital $(65 \mathrm{mg} / \mathrm{kg}$ i.p.), and were administered atropine methyl nitrate (0.4 $\mathrm{mg} / \mathrm{kg}$ i.p.) to prevent airway obstruction. After mounting in a stereotaxic apparatus (Kopf Instruments, Tujunga, CA), the scalp was incised and retracted, and lambda and bregma were placed in the same horizontal plane. Small burr holes were drilled for bilateral placement of guide cannulas $1 \mathrm{~mm}$ above the BLA $(2.3 \mathrm{~mm}$ posterior to bregma, $5.0 \mathrm{~mm}$ lateral to the midline, 6.3 $\mathrm{mm}$ ventral to dura) or CEA $(2.0 \mathrm{~mm}$ posterior to bregma, $4.0 \mathrm{~mm}$ lateral to the midline, $5.7 \mathrm{~mm}$ dorsal to dura), and placement of three small jeweler's screws. The guide cannulas were lowered, and dental acrylic was applied to the skull to hold the cannulas in place. After surgery, obturators (33 gauge; Plastics One, Roanoke, VA) were inserted into the cannulas, and the rats were returned to their home cages. The obturators were replaced every other day during the week of recovery.

\subsection{Behavioral apparatus}

Eight identical observation chambers $(30 \times 24 \times 21$ $\mathrm{cm}$; MED-Associates Inc., Burlington, VT) were used for all training and testing. The chambers were constructed of aluminum (two side walls) and Plexiglas (rear wall, ceiling, and hinged front door), and situated in sound-attenuating cabinets in an isolated room. The floor of each chamber consisted of 19 stainless steel rods (4 $\mathrm{mm}$ diameter) spaced $1.5 \mathrm{~cm}$ apart (center-tocenter). The rods were wired to a shock source and solid-state grid scrambler (MED-Associates Inc., Burlington, VT) for the delivery of footshock unconditional stimuli (USs). A speaker for delivering acoustic stimuli was mounted to a grating on one wall of each chamber.

Each conditioning chamber rested on a load-cell platform that recorded chamber displacement in response to each rat's motor activity. The output of each chamber's load cell was amplified (vernier knob $=8$ ) at a level that was previously determined to optimize the detection of freezing behavior. The load-cell amplifier output from each chamber was digitized at $5 \mathrm{~Hz}$ (yielding 300 observations per min per rat) and acquired on-line using Threshold Activity software (MED-Associates Inc., Burlington, VT). The average raw load-cell output was used to quantify activity. Freezing was quantified by calculating the number of observations below a freezing threshold [17]. Freezing was scored only if a rat was immobile for $1 \mathrm{~s}$ or longer; thus, freezing was scored only for five or more contiguous observations. For each session, the freezing observations were converted to a percentage of total observations.

All training occurred in Context A. The chambers were cleaned with a $5 \%$ ammonium hydroxide solution, and stainless steel pans with a thin layer of the same solution were placed under the grid floors before rats were placed in the chambers. Illumination was provided by both the room lights and a small stimulus light (15 $\mathrm{W})$ in each chamber, and background noise $(65 \mathrm{~dB}$, A-scale) was supplied by ventilation fans in each chest. Contextual fear testing occurred in Context A and, for auditory fear conditioning experiments, tone fear testing occurred in Context B. For Context B, a $1 \%$ acetic acid solution was used to clean the chambers and placed in the pans under the grid floor. In addition, illumination was provided only by a $15-\mathrm{W}$ red light in the room, and ventilation fans were turned off. 


\subsection{Experiment 1: dose-response analysis of the effects of intra-amygdala $\mathrm{H7}$ on contextual fear conditioning}

The subjects were 55 adult male rats. All rats received bilateral cannulas implants aimed at the BLA. After 1 week of recovery from surgery, pairs of rats were transported to the laboratory and given a mock intracranial infusion. On arrival, the obturators were removed and 33 gauge injection cannulas that extended $1 \mathrm{~mm}$ past the guide cannulas were inserted (Plastics One, Roanoke, VA). An infusion pump (Harvard Apparatus, South Natick, MA) was turned on for $2.5 \mathrm{~min}$ at a rate of $0.1 \mu \mathrm{l} / \mathrm{min}$ - no fluid was infused into the brain during the mock infusion. The pumps were then turned off, and after $1 \mathrm{~min}$, the obturators were replaced and the rats were returned to their home cages.

On the conditioning day, which occurred $24 \mathrm{~h}$ after the mock infusion, rats underwent a similar procedure, but the injection cannulas were attached to the pump with polyethylene tubing (PE-20; A-M Systems, Inc., Carlsborg, WA). Rats were administered an infusion of either vehicle (100 mM PBS, pH 7.4) or $\mathrm{H} 7$ in varying concentrations $(0.04,0.40,4.00$, or $8.00 \mathrm{mg} /$ $\mathrm{ml}$; Tocris, Ballwin, MO). This resulted in doses of 0 , $0.01,0.10,1.00$, or $2.00 \mu \mathrm{g} / \mathrm{side}$. During the infusion, the rats were prevented from grooming with finger pokes, as grooming often dislodged the injection cannulas. The rats were returned to their home cages for $15 \mathrm{~min}$ before being transported to the conditioning chambers.

Three minutes after placement in the conditioning chambers (Context $\mathrm{A}$ ), the rats received five unsignaled footshocks $(1 \mathrm{~s}, 1.0 \mathrm{~mA}, 1$-min inter-shock interval). The rats were returned to their home cages 1 min after the final shock. Fear conditioning to the context was assessed by returning the rats to the conditioning chambers $24 \mathrm{~h}$ later and assessing freezing during a 4-min extinction test. Eight rats were excluded from all analyses due to inaccurate cannula placement.

\subsection{Experiment 2: effects of BLA versus CEA infusions of $H 7$ on contextual and auditory fear conditioning}

The subjects were 45 adult male rats. Half of the rats received bilateral cannulas implants aimed at the BLA, and the other half of the rats received bilateral cannula implants aimed at the CEA. One week after surgery, rats received a mock infusion as described in Experiment 1. Twenty-four hours later, the rats were transported to the laboratory and infused with $0.25 \mu \mathrm{l}$ of either vehicle or an $8.0-\mathrm{mg} / \mathrm{ml}$ solution of $\mathrm{H} 7(2.0$ $\mu \mathrm{g}$ infused per side), as previously described. Rats were returned to their home cages for $15 \mathrm{~min}$ before placement in the conditioning chambers (Context A).

Three minutes after being placed in the chambers, rats received five tone $(10 \mathrm{~s}, 85 \mathrm{~dB}, 2 \mathrm{kHz})$-footshock ( $2 \mathrm{~s}, 1.0 \mathrm{~mA}$ shock) pairings (70 $\mathrm{s}$ inter-trial interval). The rats were returned to their home cages 1 min after the final shock. Fear conditioning to the context was assessed by returning the rats to the conditioning chambers $24 \mathrm{~h}$ later and assessing freezing during an 8-min extinction test. Fear conditioning to the tone was assessed by returning the rats to a novel context (Context B) $24 \mathrm{~h}$ after the context test, and assessing freezing during an 8 -min tone $(85 \mathrm{~dB}, 2 \mathrm{kHz})$, which was delivered 2 min after placement of the rats in the chambers. Four rats were excluded from the analyses due to inaccurate cannula placement.

\subsection{Experiment 3: analysis of the effects of intra-amygdala $\mathrm{H} 7$ on the acquisition versus expression of contextual fear conditioning}

The subjects were 32 adult male rats. All rats received bilateral cannula implants aimed at the BLA. The rats were randomly assigned to a $2 \times 2$ design, receiving either vehicle or $\mathrm{H} 7$ prior to training, and vehicle or $\mathrm{H} 7$ prior to testing. Twenty-four hours before training, the rats received a mock infusion as described in Experiment 1. On the training day, the rats were infused with $0.25 \mu \mathrm{l}$ of either vehicle or a $4-\mathrm{mg} / \mathrm{ml}$ solution of $\mathrm{H} 7(1.0 \mu \mathrm{g} / \mathrm{side})$. The rats were returned to their home cages for 15 min before placement in the conditioning chambers.

Three minutes after placement in the chambers, the rats received context conditioning as described in Experiment 1. Twenty-four hours after training, rats again received an infusion of $0.25 \mu \mathrm{l}$ of either vehicle or $4.0 \mathrm{mg} / \mathrm{ml} \mathrm{H} 715 \mathrm{~min}$ prior to a 4-min context extinction test. The rats were returned to their home cages for $15 \mathrm{~min}$ before placement in the chambers for the extinction test. Seven rats were excluded from the analyses due to either inaccurate cannula placements, or because the injectors became dislodged during the infusion process.

\subsection{Histology}

Histological verification of cannula placement was performed after behavioral testing. Rats were perfused across the heart with $0.9 \%$ saline followed by $10 \%$ formalin. Brains were removed from the skull and post-fixed in $10 \%$ formalin for 2 days and $10 \%$ formalin/ $30 \%$ sucrose until sectioning. Coronal sections (40 $\mu \mathrm{m}$ thick, taken every $160 \mu \mathrm{m}$ ) were cut on a cryostat $\left(-18^{\circ} \mathrm{C}\right)$ and wet mounted on glass microscope slides with $70 \%$ ethanol. After drying, sections were stained with $0.25 \%$ thionin to visualize cell bodies. Cannula placements were reconstructed on stereotaxic atlas templates [33]. 


\subsection{Data analysis}

For each session, the freezing data were transformed to a percentage of total observations, a probability estimate that is amenable to analysis with parametric statistics. These probability estimates of freezing were analyzed using analysis of variance (ANOVA). Posthoc comparisons in the form of Fisher's Least Significant Difference tests were performed following a significant omnibus $F$-ratio. All data are represented as means \pm the standard errors of the means (S.E.M.s).

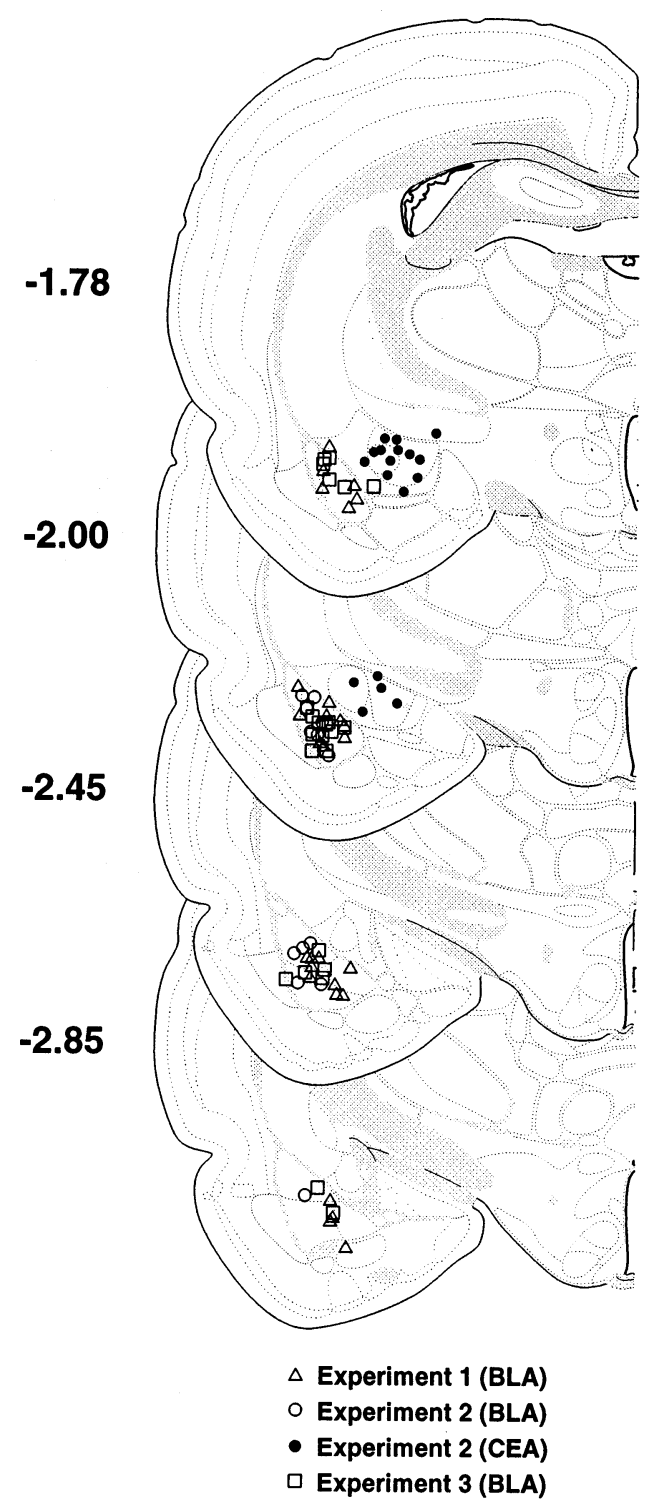

Fig. 1. Localization of injection cannula tips in the basolateral (BLA) and central (CEA) amygdala. The schematic representation of injection cannula tips is shown for all rats included in the analyses of Experiments $1-3$. The numerical values to the side of the coronal half-sections (45) indicate the position of each section in millimeters relative to bregma. a

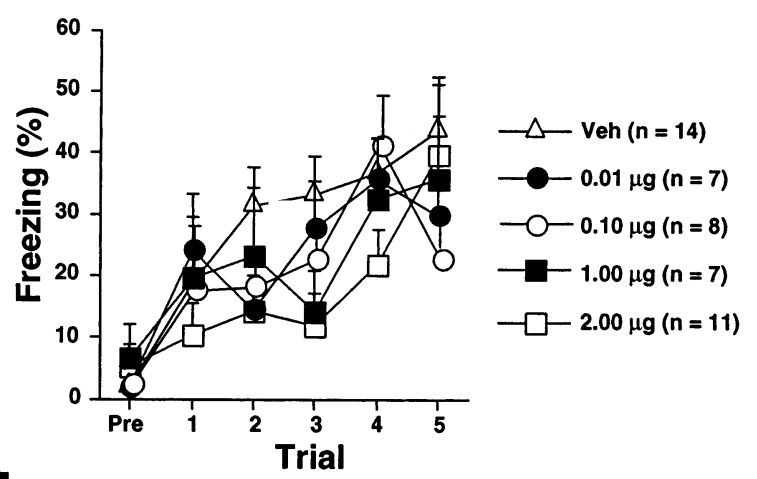

b

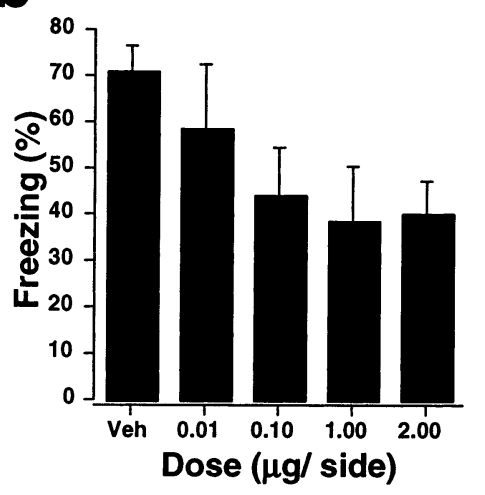

Fig. 2. Experiment 1: Dose-response analysis of the effects of intraamygdala $\mathrm{H} 7$ on contextual fear conditioning. (a) Mean percentage of freezing $( \pm$ S.E.M. $)$ exhibited on the training day, both prior to shock (Pre) and during the $1 \mathrm{~min}$ interval following each footshock (Trials 1-5) and during the 4-min context extinction test (b) in rats infused with varying doses of $\mathrm{H} 715 \mathrm{~min}$ prior to training.

\section{Results}

\subsection{Histology}

The injection cannula tip placements for all animals included in analyses are summarized in Fig. 1. Placements were bilaterally symmetrical and localized within the target amygdaloid nuclei.

\subsection{Intra-amygdala infusion of $H 7$ blocks conditional fear in a dose-dependent manner}

As shown in Fig. 2(b), intra-amygdala infusion of $\mathrm{H} 7$ into the BLA prior to fear conditioning attenuated conditional freezing to contextual cues in a dose-dependent manner. This observation was confirmed by a significant main effect of Dose $\left[F_{(4.42)}=2.9 ; P<0.05\right]$ in the ANOVA. Post-hoc comparisons $(P<0.05)$ revealed that rats infused with either $0.1,1.0$, or $2.0 \mu \mathrm{g}$ of $\mathrm{H} 7$ per side froze at significantly lower levels than rats infused with vehicle. Importantly, immediate post-shock freezing (Fig. 2(a)) was comparable across all doses of $\mathrm{H} 7$. This was confirmed in the ANOVA by the absence of a 
main effect of Group $\left[F_{(4,42)}=0.7\right]$, and a non-significant Group $\times$ Trial interaction $\left[F_{(20,210)}=1.5\right]$. Post-hoc comparisons $(P<0.05)$ revealed that all groups attained equivalent levels of asymptotic freezing. These results indicate that $\mathrm{H} 7$ does not affect the acquisition or expression of a short-term conditional fear memory assessed immediately following footshock, but does impair the acquisition of a long-term conditional fear memory assessed $24 \mathrm{~h}$ after conditioning.

\subsection{Inhibition of amygdaloid PKC/PKA attenuates both context and tone freezing in a region-specific manner}

In the second experiment, we examined the effects of $\mathrm{H} 7$ administration on the acquisition of both auditory and contextual fear. Moreover, we sought to determine whether protein kinases in the CEA also contribute to the establishment of long-term fear memories. As shown in Fig. 3, intra-BLA infusion of $\mathrm{H} 7$ caused a significant decrease in both context (Fig. 3(b)) and tone (Fig. 3(c)) freezing, whereas intra-CEA infusion of $\mathrm{H} 7$ did not affect either context or tone freezing. These observations were confirmed by a significant main effect of Group in the ANOVA for both the context $\left[F_{(2,38)}=4.9 ; P<0.01\right]$ and tone $\left[F_{(2,25)}=3.7 ; P<0.05\right]$ tests. Post-hoc comparisons $(P<0.05)$ revealed that rats infused with $\mathrm{H} 7$ in the BLA exhibited significantly lower levels of freezing than both vehicle-treated rats and rats infused with $\mathrm{H} 7$ in the CEA at nearly all time points during both context and tone testing; vehicle-treated rats and rats infused with $\mathrm{H} 7$ in the CEA did not differ from one another. Infusion of $\mathrm{H} 7$ into the BLA or CEA did not affect immediate postshock freezing on the training day (Fig. 3(a)), again indicating that $\mathrm{H} 7$ selectively affects acquisition of longterm fear memories. This was confirmed by a non-significant effect of Group in the ANOVA $\left[F_{(2,38)}=2.3\right]$, and the absence of a significant Group $\times$ Trial interaction $\left[F_{(10,190)}=1.1\right]$.
To insure that the deficits in conditional freezing in rats administered $\mathrm{H} 7$ were not due to reduced perception of the footshock unconditional stimulus (US) during training, footshock reactivity was assessed by measuring each rat's activity during the five 2-s footshocks. No differences in shock-elicited activity were observed between any groups on this measure $\left[F_{(2,25)}=\right.$ $0.9]$. To confirm that the long-term deficits in conditional tone freezing in the BLA H7 group were not caused by an impairment in the ability to process tone information during training, we assessed freezing to the tone CS on the conditioning day. Freezing to each 10-s tone was normalized by subtracting context freezing during the preceding 58-s interval. Freezing to the tone CS reliably increased over the conditioning session [significant effect of Tone Trial, $F_{(4,100)}=2.5 ; P<0.05$ ], and there was no effect of drug infusion on the acquisition of tone freezing [non-significant effect of Group, $F_{(2,25)}=0.4$; non-significant Group $\times$ Tone Trial interaction, $\left.F_{(8,100)}=0.6\right]$. This suggests that administration of $\mathrm{H} 7$ prior to training does not impair sensory processing of the tone during conditioning. Together, these results indicate that $\mathrm{H} 7$ selectively affects acquisition of long-term fear memories.

\subsection{The effects of $H 7$ are not attributable to state-dependency or performance deficits}

In the third experiment, we examined the possibility that deficits in freezing in rats trained after an intraamygdala $\mathrm{H} 7$ infusion were due to a shift in behavioral state from conditioning to testing. We assessed the state-dependency of the $\mathrm{H} 7$ effect by infusing $\mathrm{H} 7$ into the BLA before conditioning, extinction testing, or both. As shown in Fig. 4(b), PKC/PKA inhibition in the BLA disrupted the learning, but not the performance, of conditional freezing. That is, infusion of $\mathrm{H} 7$ into the BLA prior to fear conditioning produced a significant attenuation of conditional freezing, but
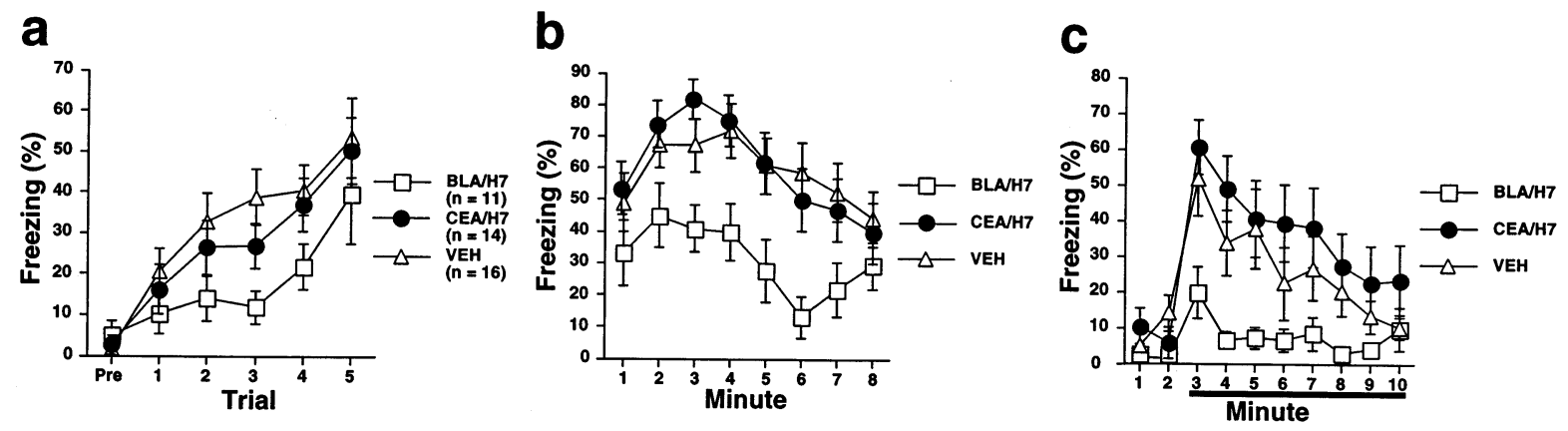

Fig. 3. Experiment 2: Effects of BLA versus CEA infusions of $\mathrm{H} 7$ on contextual and auditory fear conditioning. Mean percentage of freezing ( \pm S.E.M.) exhibited on the training day (a), the 8-min context extinction test in the training context (Context A) (b), and the 8-min tone extinction test in a novel context (Context B) (c) in rats receiving a vehicle or H7 infusion into the basolateral (BLA) or central (CEA) amygdala. There were no differences observed between rats infused with vehicle in the BLA or CEA for either contextual or tone freezing, thus the two groups were collapsed into a single 'vehicle' group for both measures. The presence of the tone is indicated by the black bar below the $x$-axis. 
a
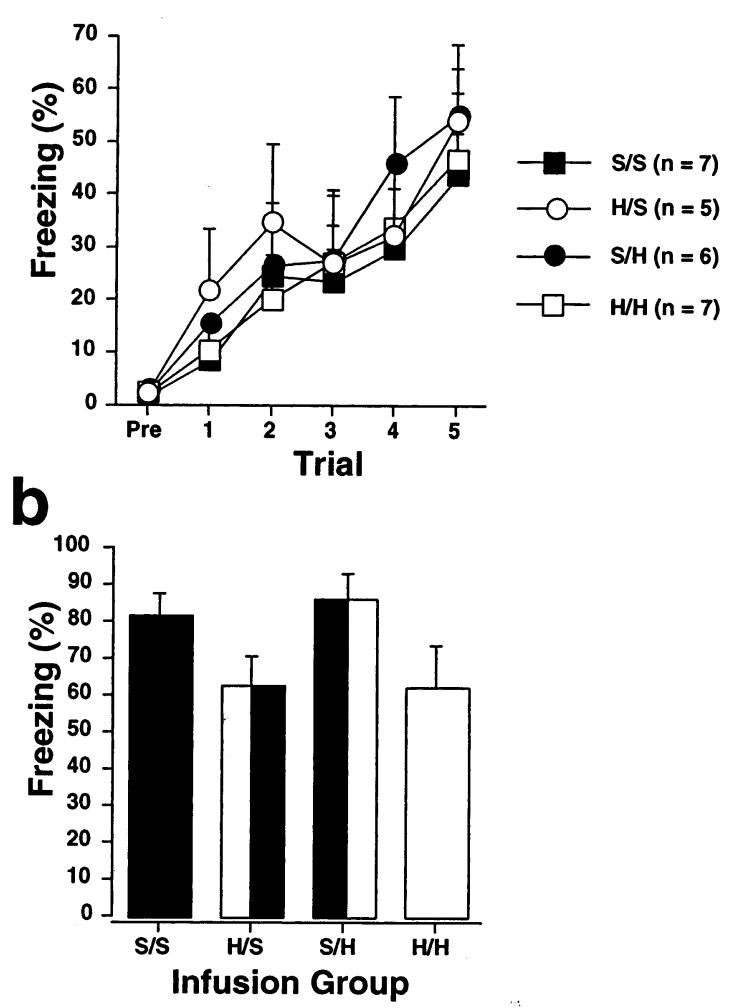

Fig. 4. Experiment 3: Analysis of the effects of intra-amygdala $\mathrm{H} 7$ on the acquisition vs. expression of contextual fear conditioning. Mean percentage of freezing $( \pm$ S.E.M.) exhibited on the training day (a) and during the 4-min context extinction test (b) in rats infused with saline $(\mathrm{S})$ or $\mathrm{H} 7 \mathrm{(H)}$ prior to training, testing, or both. $\mathrm{S} / \mathrm{S}=$ SalineSaline, $\mathrm{S} / \mathrm{H}=$ Saline-H7, H/V = H7-Saline, $\mathrm{H} / \mathrm{H}=\mathrm{H} 7-\mathrm{H} 7$.

freezing was unaffected by an infusion of $\mathrm{H} 7$ prior to extinction testing. Thus, $\mathrm{H} 7$ does not impair the processing of contextual information per se, or the performance of freezing behavior. This observation was confirmed in the ANOVA by a significant main effect of Training $\left[F_{(1,21)}=6.1 ; P<0.05\right]$, and a non-significant main effect of Testing $\left[F_{(1,21)}=0.2\right]$. The non-significant Training $\times$ Testing interaction $\left[F_{(1,21)}=0.01\right]$ indicated that the conditional freezing deficits produced by intra-amygdaloid $\mathrm{H} 7$ were not state-dependent. As in Experiments 1 and 2, commensurate levels of immediate post-shock freezing were observed for all groups on the training day (Fig. 4(a)). This was confirmed by the absence of both a main effect of Group $\left[F_{(3,21)}=\right.$ $0.4]$ and a Group $\times$ Trial interaction $\left[F_{(15,105)}=0.3\right]$ in the ANOVA. Again, this indicates that the differences in conditional freezing observed on the testing day were likely due to effects of the drug on long-term memory consolidation. In none of the experiments did intraamygdaloid $\mathrm{H} 7$ affect motor activity prior to footshock or footshock sensitivity (data not shown). Thus, our experiments reveal that inhibition of PKA and PKC activity in the BLA, but not CEA, produces a selective deficit in the acquisition of long-term memories for both auditory and contextual fear.

\section{Discussion}

In the present study, we examined the role of amygdaloid protein kinases in the acquisition and expression of fear memories by using direct intra-amygdaloid infusion of $\mathrm{H} 7$, a PKC/PKA inhibitor. The results revealed that infusion of $\mathrm{H} 7$ into the BLA produces a dose-dependent attenuation of contextual fear conditioning (Experiment 1) and that $\mathrm{H} 7$ attenuates the acquisition of both auditory and contextual fear (Experiment 2). Intra-amygdala infusion of $\mathrm{H} 7$ impaired the learning as opposed to the performance of conditional fear to the extent that pre-testing infusions of $\mathrm{H} 7 \mathrm{did}$ not affect the expression of conditional freezing (Experiment 3). Moreover, the effects of $\mathrm{H} 7$ were selective for long-term fear memories insofar as immediate postshock freezing, a measure of short-term fear memory, was not affected by intra-amygdala $\mathrm{H} 7$ infusion. Our results also demonstrate that the BLA is the critical locus of PKA and PKC activity within the amygdala during fear conditioning - infusion of $\mathrm{H} 7$ into the CEA did not affect the acquisition of fear conditioning (Experiment 2). Collectively, these findings extend earlier work using intracerebroventricular administration of protein kinase inhibitors $[2,31]$ and identify a critical role for protein kinase activity in the BLA in the acquisition of longterm conditional fear memories.

The important role for amygdaloid protein kinase activation in establishing long-term fear memories is not surprising given the sensitivity of fear conditioning to NMDA receptor blockade $[11,21,25]$. Unlike NMDA receptor blockade, however, protein kinase inhibition in the amygdala produced a selective deficit in the acquisition, but not expression, of conditional fear memories. This suggests that the effects of NMDA receptor antagonists on both the acquisition and expression of fear conditioning are more likely related to reductions in cell excitability produced by the antagonists $[13,22]$ rather than a specific impairment in LTP induction. Although we did not assess the effects of $\mathrm{H} 7$ on amygdaloid cell excitability, it is unlikely that $\mathrm{H} 7$ produced its effects on fear conditioning through a non-specific attenuation of amygdaloid activity. That is, in contrast to neurotoxic amygdala lesions $[17,18,20]$, H7 did not affect either the expression of immediatepostshock freezing on the conditioning day or the expression of conditional freezing during retention testing.

Based on the available evidence, it seems reasonable to speculate that $\mathrm{H} 7$ attenuated the acquisition of longterm conditional fear memories by impairing the induction of amygdaloid LTP. Several recent reports are 
consistent with a role for LTP in the acquisition of Pavlovian fear conditioning (see Ref. [19] for a review). Indeed, the selective effect of $\mathrm{H} 7$ on the acquisition of long-term conditional fear is consistent with the role PKA and PKC have been demonstrated to play in the induction of the late phase of LTP (L-LTP) in the CA1 region of the hippocampus $[6,8,15]$ (see Ref. [34] for a review). Although it is not known whether protein kinase activity in the amygdala is involved in the induction of L-LTP, there is some evidence for a role for PKA in the expression of an early phase of amygdaloid LTP [7]. Further work is required to understand the specific contribution of protein kinase activity to amygdaloid LTP. Nonetheless, current data are consistent with the view that intra-amygdala kinase inhibitors attenuate long-term memory formation by disrupting the induction of L-LTP in amygdala neurons.

In contrast to the important role for PKA and PKC in the induction of LTP, these enzymes do not appear to be involved in the expression or maintenance of L-LTP, at least in the hippocampus [14,15]. Based on this evidence, one would not expect PKA/PKC inhibitors to affect the expression of long-term conditional fear memories, which are presumably dependent on late phase LTP in the amygdala [19]. Consistent with this prediction, we found that intra-amygdala $\mathrm{H} 7$ infusions did not affect the expression of conditional freezing when administered 15 min prior to a retention test, which was conducted $24 \mathrm{~h}$ after fear conditioning. It has also been reported that PKA/PKC activity is not required for the induction or expression of either posttetanic $(<10 \mathrm{~min})$ or short-term $(<1 \mathrm{~h})$ potentiation. This finding is consistent with our observation of normal immediate post-shock freezing in rats trained after infusion of $\mathrm{H} 7$ into the BLA. Thus, our results support the view that PKA/PKC-independent forms of plasticity underlie the short-term fear memories required for immediate post-shock freezing [16]. Considering all of our results, it is apparent that the temporal profile of the conditional fear deficits we observed in rats infused with $\mathrm{H} 7$ closely parallels the temporal profile of synaptic plasticity deficits observed after inhibition of PKA and PKC.

It should be noted that other protein kinases, including mitogen-activated protein kinase (MAPK) $[1,30]$ and $\mathrm{Ca}^{2+}$-calmodulin-dependent kinase (CaMKII) [23] have been implicated in Pavlovian fear conditioning. The involvement of these other kinase pathways in fear conditioning might explain the partial attenuation of conditional freezing that we have observed after PKA/ PKC inhibition in the BLA. Thus, the MAPK and CaMKII pathways may be capable of supporting some degree of fear conditioning in the absence of PKA and PKC activity. Work is currently underway in our laboratory to determine the relative contributions of amygdaloid PKA, PKC, MAPK, and CaMKII to fear conditioning using inhibitors selective for each of these kinases.

In sum, the present results reveal an important role for amygdaloid PKA and PKC in the acquisition of long-term, but not short-term, conditional fear memories. The involvement of amygdaloid PKA and PKC in the acquisition of conditional fear provides additional support for a role for amygdaloid LTP in this form of learning. Collectively, these results provide important new insight into the intracellular biochemical cascades underlying amygdala-dependent memory formation during Pavlovian fear conditioning in rats.

\section{Acknowledgements}

This research was supported by a grant from the NIMH (MH57865) to S. Maren. K.A. Goosens is a Howard Hughes predoctoral fellow. The authors would like to thank Bryan Faller for technical assistance.

\section{References}

[1] Atkins CM, Selcher JC, Petraitis JJ, Trzaskos JM, Sweatt JD. The MAP kinase cascade is required for mammalian associative learning. Nat Neurosci 1998;1:602-9.

[2] Bourtchouladze R, Abel T, Berman N, Gordon R, Lapidus K, Kandel ER. Different training procedures recruit either one or two critical periods for contextual memory consolidation, each of which requires protein synthesis and PKA. Learn Mem 1998;5:365-74.

[3] Brambilla R, Gnesutta N, Minichiello L, White G, Roylance AJ, Herron CE, Ramsey M, Wolfer DP, Cestari V, Rossi-Arnaud C, Grant SG, Chapman PF, Lipp HP, Sturani E, Klein R. A role for the Ras signaling pathway in synaptic transmission and long-term memory. Nature 1997;390:281-6.

[4] Clugnet MC, LeDoux JE. Synaptic plasticity in fear conditioning circuits: induction of LTP in the lateral nucleus of the amygdala by stimulation of the medial geniculate body. J Neurosci 1990;10:2918-24.

[5] Fanselow M, LeDoux JE. Why we think plasticity underlying Pavlovian fear conditioning occurs in the basolateral amygdala. Neuron 1999;23:229-32.

[6] Frey U, Huang YY, Kandel ER. Effects of cAMP stimulate a late stage of LTP in hippocampal CA1 neurons. Science 1993;260:1661-4.

[7] Huang YY, Kandel ER. Postsynaptic induction and PKA-dependent expression of LTP in the lateral amygdala. Neuron 1998;21:169-78.

[8] Huang YY, Li X, Kandel ER. cAMP contributes to mossy fiber LTP initiating both a covalently mediated early phase and macromolecular synthesis-dependent late phase. Cell 1994;79:69-79.

[9] Impey S, Obrietan K, Wong ST, Poser S, Yano S, Wayman G, Deloulme JC, Chan G, Storm DR. Cross talk between ERK and PKA is required for $\mathrm{Ca}^{2+}$ stimulation of CREB-dependent transcription and ERK nuclear translocation. Neuron 1998;21:869-83.

[10] Impey S, Smith DM, Obrietan K, Donahue R, Wade C, Storm DR. Stimulation of cAMP response element (CRE)-mediated transcription during contextual learning. Nat Neurosci 1998;1:595-601. 
[11] Lee H, Kim JJ. Amygdalar NMDA receptors are critical for new fear learning in previously fear-conditioned rats. J Neurosci 1998; 18:8444-54.

[12] Lee Y, Walker DL, Davis M. Lack of a temporal gradient of retrograde amnesia following NMDA-induced lesions of the basolateral amygdala assessed with the fear-potentiated startle paradigm. Behav Neurosci 1992;110:836-9.

[13] Li XF, Phillips R, LeDoux JE. NMDA and non-NMDA receptors contribute to synaptic transmission between the medial geniculate body and the lateral nucleus of the amygdala. Exp Brain Res 1995;105:87-100.

[14] Malenka RC, Kauer JA, Perkel DJ, Mauk MD, Kelly PT, Nicoll RA, Waxham MN. An essential role for postsynaptic calmodulin and protein kinase activity in long-term potentiation. Nature 1989;340:554-7.

[15] Malinow R, Schulman H, Tsien RW. Inhibition of postsynaptic PKC or CaMKII blocks induction but not expression of LTP. Science 1989;245:862-6.

[16] Maren S. Synaptic transmission and plasticity in the amygdala: an emerging physiology of fear conditioning circuits. Mol Neurobiol 1996;13:1-22.

[17] Maren S. Overtraining does not mitigate contextual fear conditioning deficits produced by neurotoxic lesions of the basolateral amygdala. J Neurosci 1998;18:3088-97.

[18] Maren S. Neurotoxic basolateral amygdala lesions impair learning and memory but not the performance of conditional fear in rats. J Neurosci 1999;19:8696-703.

[19] Maren S. Long-term potentiation in the amygdala: a mechanism for emotional learning and memory. Trends Neurosci 1999;22:561-7.

[20] Maren S, Aharonov G, Fanselow MS. Retrograde abolition of conditional fear after excitotoxic lesions in the basolateral amygdala of rats: absence of a temporal gradient. Behav Neurosci 1996;110:718-26.

[21] Maren S, Aharonov G, Stote DL, Fanselow MS. $N$-methyl-D-aspartate receptors in the basolateral amygdala are required for both acquisition and expression of conditional fear in rats. Behav Neurosci 1996;110:1365-74.

[22] Maren S, Fanselow MS. Synaptic plasticity in the basolateral amygdala induced by hippocampal formation stimulation in vivo. J Neurosci 1995;15:7548-64.
[23] Mayford M, Bach ME, Huang YY, Wang L, Hawkins RD, Kandel ER. Control of memory formation through regulated expression of a CaMKII transgene. Science 1996;274:1678-83.

[24] McKernan MG, Shinnick-Gallagher P. Fear conditioning induces a lasting potentiation of synaptic currents in vitro. Nature 1997;390:607-11.

[25] Miserendino MJ, Sananes CB, Melia KR, Davis M. Blocking of acquisition but not expression of conditioned fear-potentiated startle by NMDA antagonists in the amygdala. Nature 1990;345:716-8.

[26] Quirk GJ, Armony JL, LeDoux JE. Fear conditioning enhances different temporal components of tone-evoked spike trains in auditory cortex and lateral amygdala. Neuron 1997;19:613-24.

[27] Quirk GJ, Repa JC, LeDoux JE. Fear conditioning enhances short-latency auditory responses of lateral amygdala neurons: parallel recordings in the freely behaving rat. Neuron 1995; 15:1029-39.

[28] Rogan MT, LeDoux JE. LTP is accompanied by commensurate enhancement of auditory evoked responses in a fear conditioning circuit. Neuron 1995;15:127-36.

[29] Rogan MT, Staubli UV, LeDoux JE. Fear conditioning induces associative long-term potentiation in the amygdala. Nature 1997;390:604-7.

[30] Schafe GE, Atkins CM, Swank MW, Sweatt JD, LeDoux JE. Activation of MAP kinase in the rat lateral and basal amygdala following Pavlovian fear conditioning. Soc Neurosci Abstr 1999;25:879.

[31] Schafe GE, Nadel NV, Sullivan GM, Harris A, LeDoux JE. Memory consolidation for contextual and auditory fear conditioning is dependent on protein synthesis, PKA, and MAP kinase. Learn Mem 1999;6:97-110.

[32] Shors TJ, Elkabes S, Selcher JC, Black IB. Stress persistently increases NMDA receptor-mediated binding of $\left[{ }^{3} \mathrm{H}\right] \mathrm{PDBu}$ (a marker for protein kinase $\mathrm{C}$ ) in the amygdala, and re-exposure to the stressful context reactivates the increase. Brain Res 1997;750:293-300.

[33] Swanson LW. Brain Maps: Structure of the Rat Brain, 2nd ed. Amsterdam: Elsevier, 1999.

[34] Sweatt JD. Toward a molecular explanation for long-term potentiation. Learn Mem 1999;6:399-416. 